\title{
Sepsis Awareness in India from Internet Search Trends: Where Do We Stand?
}

Sir,

Sepsis is defined as a life-threatening organ dysfunction caused by a dysregulated host response to infection. The incidence of sepsis has shown a steady upward trend across recent years. In the USA alone, it accounted for more than 20 billion US dollars in hospital costs in 2011. ${ }^{[1]}$ Recognizing the gravity of the situation a Task force was constituted by the European Society of Intensive Care Medicine and the Society of Critical Care Medicine that has come up with a more effective operational definition of sepsis. The new definition is expected to be ease identification of patients with sepsis or at risk of developing sepsis thereby helping in better management and improved outcome. ${ }^{[2]}$ In India, the scenario is equally alarming with one in four patients admitted to the Intensive Care Unit (ICU) developing severe sepsis or septic shock with an estimated mortality of $>50 \%{ }^{\left[{ }^{[3]}\right.}$

The population in India is a relatively young one, and as much as $34 \%$ of the population have access to the internet. We searched Google Trends for Indian data over the last 12 months to evaluate internet searches about sepsis. After determining search terms primarily related to sepsis, we compared search volume over the past 12 months using search terms including (sepsis), (ICU) and (ECMO). Our results were quite interesting. We found that average search volumes for all three terms remained dismally low throughout the year [Table 1 and Figure 1]. However, interest in the search terms of sepsis and extracorporeal membrane oxygenation (ECMO) has shown peaks at the beginning of October and December, respectively [Figure 1]. The Indian internet populace's renewed interest in sepsis could be related to the hospitalization and subsequent unfortunate demise of much loved Honorable ex-Chief Minister of Tamil Nadu Ms. J. Jayalalitha during this period. The sepsis-related terms which showed a rising search volume during the last 1 year is shown in Table 2 . However, notwithstanding the peaks, interest in sepsis-related searches remain quite low in India compared to global averages over the last 1 year [Figure 2 and Table 2]. When we analyzed by subregions, we found that the states of Tamil Nadu and Andhra Pradesh were ahead of national average in searches for "sepsis," with the maximum number of searches for "sepsis" and "ECMO" emanating from Andhra Pradesh and Tamil Nadu, respectively [Figure 3]. Findings from this analysis provide valuable insight into internet use of Indians in gaining sepsis-related information. We need to capitalize on the renewed interest in sepsis during the latter half of the year as evident from the internet searches and create greater public consciousness about this dreaded condition. The burden of tropical infectious disease in India is huge and economic resources scarce. ${ }^{[4]}$ The public and health personnel need to

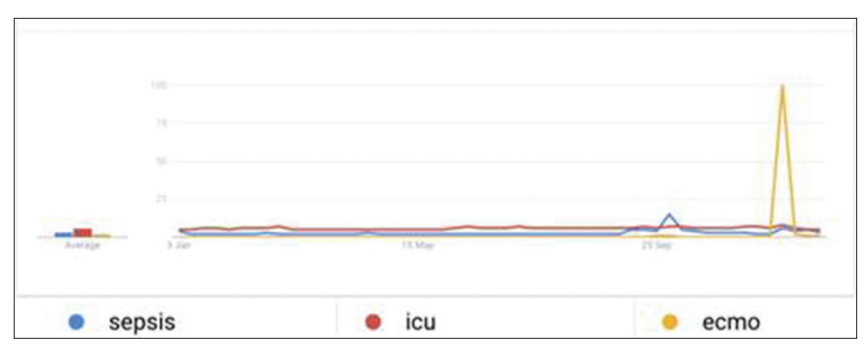

Figure 1: Internet searches over time in relation to sepsis in India (reproduced from https://www.google.co.in/trends/explore?date =today $\% 20$ $12-\mathrm{m} \& g e 0=I N \& q=$ sepsis, icu,ecmo)

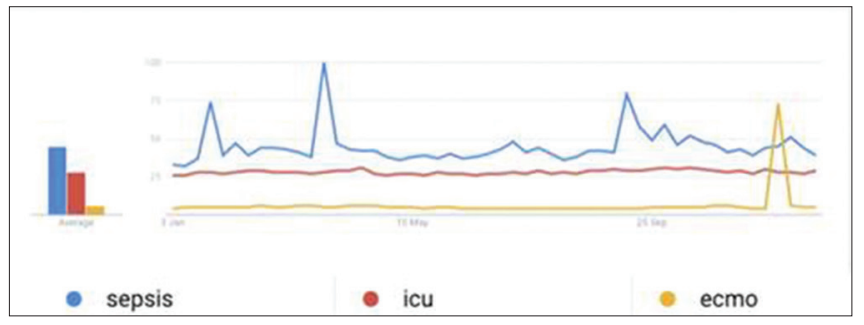

Figure 2: Internet searches over time in relation to sepsis globally (reproduced from https://www.google.co.in/trends/explore?date = today $\% 20$ $12-m \& q=$ sepsis, icu,ecmo)

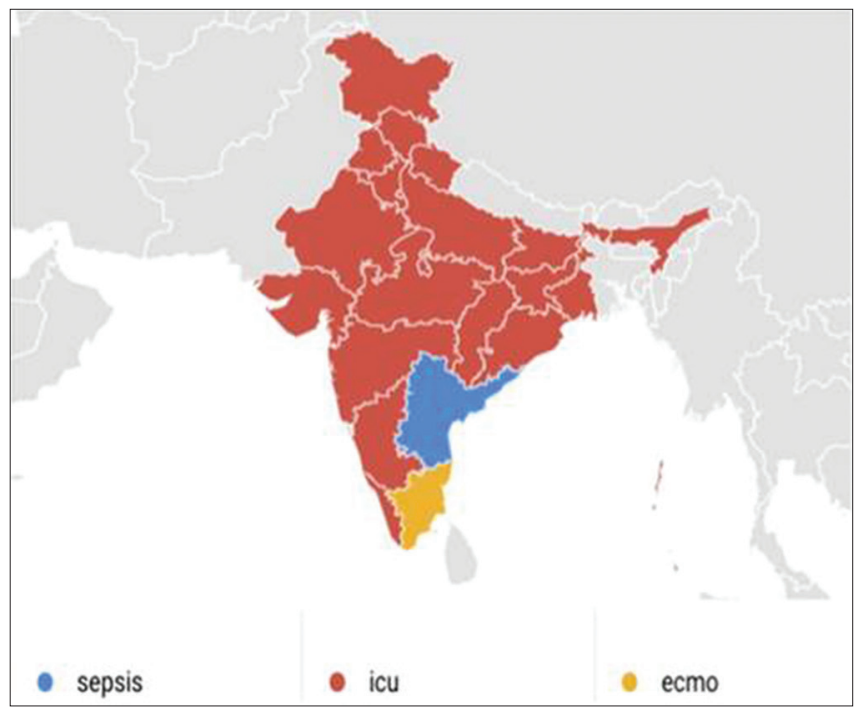

Figure 3: Internet searches over last 12 months analysed at the state level (reproduced from https://www.google.co.in/trends/ explore?date $=$ today $\% 2012-\mathrm{m} \&$ geo $=\mid \mathrm{N} \& \mathrm{q}=$ sepsis, $, \mathrm{cu}, \mathrm{ecmo}$

be made aware of the severe threats imposed by sepsis so that preventive measures are undertaken more vigorously, and measures to halt its progression are implemented at an earlier stage before multiorgan dysfunction sets in. 


\begin{tabular}{lcc}
\hline Table 1: Average search index over the last & $\mathbf{1 2}$ months \\
\hline Search Term & India & Worldwide \\
\hline Sepsis & 3 & 45 \\
ICU & 6 & 28 \\
ECMO & 2 & 6 \\
\hline
\end{tabular}

Table 2: Top search terms related to sepsis over last 12 months in India

\begin{tabular}{lc} 
Search Terms & Average Search Index \\
\hline Sepsis meaning & 100 \\
Sepsis guidelines & 55 \\
What is Sepsis & 40 \\
Sepsis disease & 40 \\
Sepsis icd 10 & 40 \\
Neonatal Sepsis & 40 \\
Sepsis treatment & 35 \\
Sepsis guidelines 2016 & 30 \\
Sepsis symptoms & 30 \\
Jayalalitha & 25 \\
Puerperal Sepsis & 25 \\
Severe Sepsis & 25 \\
Sepsis syndrome & 25 \\
Sepsis definition & 25 \\
Sepsis means & 20 \\
Meaning of sepsis & 20 \\
Surviving sepsis guidelines & 15 \\
Septic shock & 15 \\
Septicemia & 15 \\
Jayalalitha news & 10 \\
Richard Beale & 10 \\
Symptoms of Sepsis & 10 \\
SIRS & 10 \\
Jayalalitha latest news & 5 \\
\hline
\end{tabular}

The internet is a powerful tool of communication today allowing an easier, cheaper and faster access, and dissemination of information. Hence, we need to use the internet and social media in generating interest and creating public awareness in the importance of prevention, early detection and timely management of this life-threatening condition.

\section{Financial support and sponsorship}

Nil.

\section{Conflicts of interest}

There are no conflicts of interest.

Riddhi Kundu, Puneet Khanna Department of Anaesthesiology, Pain Medicine and Critical Care, All India Institute of Medical Sciences, New Delhi, India

Address for correspondence: Dr. Puneet Khanna, Department of Anaesthesiology, Pain Medicine and Critical Care, All India Institute of Medical Sciences, New Delhi, India. E-mail:k.punit@yahoo.com

\section{References}

1. Torio CM, Andrews RM. National Inpatient Hospital Costs: The Most Expensive Conditions by Payer, 2011. Statistical Brief \#160. Healthcare Cost and Utilization Project (HCUP) Statistical Briefs; August, 2013 Available from: http:/www.ncbi.nlm.nih.gov/books/NBK169005/.

2. Singer M, Deutschman CS, Seymour CW, Shankar-Hari M, Annane D, Bauer M, et al. The third international consensus definitions for sepsis and septic shock (Sepsis-3). JAMA 2016;315:801-10.

3. Divatia JV, Amin PR, Ramakrishnan N, Kapadia FN, Todi S, Sahu S, et al. Intensive care in India: The Indian intensive care case mix and practice patterns study. Indian J Crit Care Med 2016;20:216-25.

4. Divatia JV. Caring for the critically ill in developing countries: A perspective from India. Rev Bras Ter Intensiva 2015;27:7-9.

This is an open access article distributed under the terms of the Creative Commons Attribution-NonCommercial-ShareAlike 3.0 License, which allows others to remix, tweak, and build upon the work non-commercially, as long as the author is credited and the new creations are licensed under the identical terms.

\begin{tabular}{|l|l|}
\hline \multicolumn{3}{|c|}{ Access this article online } \\
\hline Quick Response Code: & Website: \\
& www.ijccm.org \\
\cline { 2 - 2 } & \\
\end{tabular}

How to cite this article: Kundu R, Khanna P. Sepsis awareness in India from internet search trends: Where do we stand?. Indian J Crit Care Med 2017;21:616-7.

CC 2017 Indian Journal of Critical Care Medicine | Published by Wolters Kluwer - Medknow 